\title{
A palhaçaria hospitalar como conjunto de técnicas e sensibilidades: entrevista com Luciana Viacava
}

DAIANI CEZIMBRA SEVERO ROSSINI BRUM

Daiani Cezimbra Severo Rossini Brum é palhaça e doutoranda em Teatro (UDESC). Dedica-se à atuação palhacesca hospitalar junto ao grupo Doutores Risonhos (Chapecó, SC), à criação artística autoral com a Cia Lunáticas de Palhaças (Florianópolis, SC), às ações artísticas, teóricas, formativas e de pesquisa na área de Artes Cênicas. Tem experiência em interpretação teatral, máscaras, iluminação cênica, pesquisa e palhaçaria com ênfase na atuação de mulheres e nas poéticas dos contextos hospitalares.

AFILIAÇÃO - Universidade do Estado de Santa Catarina (UDESC) - Santa Catarina - Brasil http://lattes.cnpq.br/6728284014151656 


\section{- RESUMO}

O presente trabalho traz uma entrevista realizada com a artista Luciana Viacava, que trabalha como palhaça na Organização Não Governamental (ONG) Doutores da Alegria desde 2006. No intuito de contextualizar o universo de práticas pesquisadas pela entrevistada, faz-se uma breve introdução sobre essa manifestação cênica, intercalada com a história dos Doutores da Alegria, maior Organização de palhaçaria hospitalar do Brasil e uma das maiores do mundo, bem como sobre a trajetória que conduziu Luciana até a ONG. Na entrevista a artista compartilha vivências palhacescas com ênfase nos contextos hospitalares, trazendo questões e contribuições para a reflexão desse fenômeno de forte difusão nas últimas três décadas no Brasil. Quais são os desafios dessa contemporânea e crescente modalidade de atuação? Quais são as diferenças e semelhanças entre a atuação no contexto hospitalar e em outros espaços da sociedade? Essas e outras questões são abordadas por Luciana Viacava, que ao tecer essas palavras, teve como pano de fundo as suas experiências pessoais e pesquisas enquanto palhaça e artista da comicidade.

\section{PALAVRAS-CHAVE}

Palhaçaria, hospital, entrevista, Luciana Viacava.

\section{ABSTRACT}

The present work brings an interview with the artist Luciana Viacava, who works as a clown in the Non-Governmental Organization (NGOs) Doutores da Alegria since 2006. In order to contextualize the universe of practices researched by the interviewee, a brief introduction is made about this a scenic manifestation interspersed with the history of Doutores da Alegria, the largest hospital organization in Brazil and one of the largest in the world, as well as the trajectory that led Luciana to the NGO. In the interview, the artist shares clownig experiences with emphasis in the hospital contexts, bringing questions and contributions to the reflection of this phenomenon of strong diffusion in the last three decades in Brazil. What are the challenges of this contemporary and increasing modality of performance? What are the differences and similarities between the performance in the hospital context and in other spaces of society? These and other issues are approached by Luciana Viacava, who as she weaves these words, had as background her personal experiences and research as a clown and comedy artist.

\section{KEYWORDS}

Clown, hospital, interview, Luciana Viacava. 
Este trabalho trata-se da transcrição de uma entrevista cedida pela atriz e palhaça Luciana Viacava, bem como de uma apresentação sobre a artista e sua instituição de trabalho, a Organização Não Governamental (ONG) Doutores da Alegria. No intuito de contextualizar o trabalho cênico sobre o qual Luciana Viacava discorre na presente entrevista, trazemos algumas discussões sobre tal manifestação artística, intercalada com a história da ONG.

A atuação de palhaças e de palhaços no contexto hospitalar passou por um movimento de expansão nas últimas décadas no Brasil (BRUM, 2017). Atualmente, entre grupos compostos por profissionais das Artes Cênicas; grupos de pessoas pertencentes a outras áreas, que desenvolvem interesse e prática na palhaçaria hospitalar e grupos mistos entre profissionais e aprendizes, somam-se centenas de grupos pelo país (DOUTORES DA ALEGRIA, 2016).

O foco aqui é colocado sobre a investigação profissional dessa prática a partir da experiência de Luciana Viacava nos Doutores da Alegria, uma das maiores e mais completas Organizações mundiais de palhaçaria hospitalar. A ONG nasceu na capital de São Paulo em 1991, promovendo de modo ininterrupto, desde então, atividades artísticas, formativas e de pesquisa. A ONG também possui uma sede em Recife (PE).

Leiamos o posicionamento de Wellington Nogueira, fundador dos Doutores da Alegria, sobre esse tipo de manifestação teatral:

O teatro para mim ainda é um templo, ainda é um espaço sagrado, mas o que eu aprendi com isto é que quando você tem dois artistas muito tranquilos e seguros no que eles estão fazendo, como eles estão fazendo, o templo pode ser reproduzido em qualquer lugar, em qualquer circunstância da vida, inclusive a cotidiana, para justamente provocar no cotidiano uma ruptura e aí poder entrar a arte, entrar outra forma de ver o mundo, de se relacionar com a vida (NOGUEIRA, 2015, s.p., apud BRUM, 2017, p. 64).

Na fala de Wellington Nogueira fica evidente a preocupação com a transposição de um contexto artístico para a sensibilidade do cotidiano em momentos de relação com a vida das pessoas situadas no tempo e no espaço do hospital. Promovendo novos pontos de vista sobre a realidade, as Doutoras palhaças e os Doutores palhaços ${ }^{1}$ propõem maneiras distintas de relação com as Artes Cênicas, e também com o dia-a-dia dos hospitais.

Diferente do que ocorre nos contextos teatrais e circenses, a atuação nos espaços hospitalares vai ao encontro das espectadoras e dos espectadores, que se tornam, muitas vezes, como veremos na fala de Luciana, protagonistas da ação.

\footnotetext{
1 Os Doutores da Alegria, inspirados na proposição de Michael Chistensen, do Programa Clown Care Organização palhacesca hospitalar (Estados Unidos), e do médico e palhaço Patch Adams, propõem a paródia do médico e da médica como pretexto para suas interações com as pessoas em situação hospitalar. O jaleco branco e alguns termos, a exemplo de 'besteirologia', foram incorporados ao repertório palhacesco da ONG no sentido de brincar com a questão do palhaço no hospital (BRUM, 2017). Essa proposta de trabalho também é investigada no trabalho de diversos grupos de atuação palhacesca hospitalar, dentre eles, Doutores Risonhos (Chapecó, SC); Agentes do Riso (Florianópolis, SC); Trupe da Saúde (Curitiba, PR); Operação do Riso (São Paulo, SP); Hospitalhaços (Campinas, SP); Doutores Palhaços (Fortaleza, CE); Trupe Nariz Vermelho (Rio Branco, AC); Projeto Risoterapia (Santarém, PA); La Rire Medicin (França); Operação do Riso (Portugal); Payasospital (Espanha); Payasos de Hospital (Argentina), entre outros.
} 
Nos quartos, enfermarias, corredores e nas salas de espera, os transeuntes ocasionais, a equipe do hospital, os acompanhantes e as pessoas hospitalizadas são interpeladas pela ação cênica, convidadas a participar e/ou observar o seu desenvolvimento.

Com elenco de palhaças e palhaços composto por profissionais das Artes Cênicas, a ONG Doutores da Alegria desenvolveu e desenvolve pesquisa práticas, teóricas e formativas sobre a palhaçaria hospitalar, investigando uma modalidade de atuação que mescla técnicas e sensibilidades na realização de encontros positivamente efetivados. A Escola de Palhaços dos Doutores da Alegria, por exemplo, foi fundada em 2003 e desenvolve desde o mesmo ano o Programa de Formação em Palhaçaria para Jovens (PFPJ), atualmente em sua oitava turma bienal, além de outros cursos; o Programa Palhaços em Rede, ainda, visa conectar os grupos que atuam no contexto hospitalar, realizando encontros e eventos nacionais e internacionais; a realização de publicações, como as quatro edições dos Cadernos Boca Larga, que reúnem artigos, relatos, entrevistas e dramaturgias hospitalares também foram atividades realizadas pela ONG, assim como o livro Soluções de Palhaços, escrito por Morgana Masetti (1998), coordenadora de pesquisa dos Doutores da Alegria.

A ONG tornou-se referência nacional e internacional na atuação palhacesca em contextos hospitalares, tendo recebido diversos reconhecimentos, tais como:

[...] o prêmio Universidade de São Paulo de Direitos Humanos em 2005, o Stockholm Partnerships Award em 2002, o Prêmio Camargo Correa em 2004, e o Prêmio de Dubai, outorgado pela Divisão Habitat da Organização das Nações Unidas (ONU), que os classificou entre as 40 melhores práticas sociais do mundo, colocando os Doutores da Alegria na lista das 100 melhores práticas globais em 1998 e 2000 (SENA, 2011, p. 34).

Dentre as trabalhadoras e trabalhadores dos Doutores da Alegria está Luciana Viacava, que vive a palhaça Lola Brígida em diversos contextos da sociedade. Nos palcos hospitalares, teatros, no circo, nas ruas e nos hospitais manifesta-se sua pesquisa na área da palhaçaria ao longo de mais de vinte anos como artista.

Luciana Viacava compôs uma palhaça que transita entre o mundo real e o fictício tendo por principal veículo a abertura para a comunicação e a investigação da comicidade gestual. Lola Brígida, para Luciana, traz uma enorme liberdade de ser, potencializa seu lado mais ridículo, coloca em evidência o erro, a feiura e a inadequação. E ao ser posta em situações de jogo manifesta suas sensibilidades na constituição de um espaço de encontro entre o teatro e a vida, apoiada em aspectos técnicos do estudo da palhaçaria.

Formou-se no Teatro Escola Célia Helena em São Paulo, na École Internationale de Thêatre Jacques Lecoq em Paris e na Kiklos Scuola em Padova/Itália, onde também participou do workshop The Body of Movement com Norman Taylor. Estudou com Donato Sartori no Centro Maschere e Strutture Gestuali (Padova/Italia). Aprofundou-se na linguagem do palhaço com diversos profissionais como Cristiane Paoli Quito, Bete Dorgam, Luis Carlos Vasconcelos, Jos Houben, Cia. La Mínima, Phillippe Gaulier, Fernando Vieira, Avner Eisenberg, entre outros. 
Trabalha com preparação para atores em diversas companhias. Dirigiu os espetáculos: As Três Mulheres Sabidas ao lado de André Garolli da Cia. Dedo de Prosa, Divagar e Sempre da dupla de palhaças Las Cabaças, Alvorada do Centro de Pesquisa da Máscara, Choque Rosa do Circo di SóLadies e Aurora e o Tempo, ao lado de Fernando Escrich.

Foi professora de Teatro Físico no CEFAC (Centro de Formação em Artes Circences) e do Curso de Humor da SP Escola de Teatro. Como atriz trabalhou nos grupos As Meninas do Conto, Cia. Vagalum, Cia. Fraternal de Arte e Malasartes, Cia. As Graças, entre outros. Foi uma das fundadoras da Cia. do Ó, com pesquisa na palhaçaria feminina.

Hoje é formadora na Escola de Palhaços dos Doutores da Alegria, e ministra oficinas livres de máscara neutra, máscaras da comédia humana, máscaras larvárias e utilitárias, bufão e palhaço. É palhaça integrante dos Doutores da Alegria desde 2006 atuando em hospitais, espetáculos e eventos, é integrante do Coletivo Sampalhaças, atua como palhaça no Piccolo Circo Teatro de Variedades e realiza intervenções com os Palhaços Sem Fronteiras Brasil..

Nas páginas que se seguem trazemos a transcrição na íntegra da entrevista cedida pela artista que relaciona seu trabalho como palhaça aos contextos hospitalares, onde atua desde 2006. Realizado no dia 28 de setembro de 2015 por meio de uma videoconferência entre entrevistada e entrevistadora, revisado e organizado para publicação em 2019, o diálogo aqui registrado oferece diversas contribuições para a reflexão e investigação sobre o fenômeno da atuação palhacesca hospitalar. Abaixo (Figura 1) observamos Luciana em momento de atuação palhacesca hospitalar:

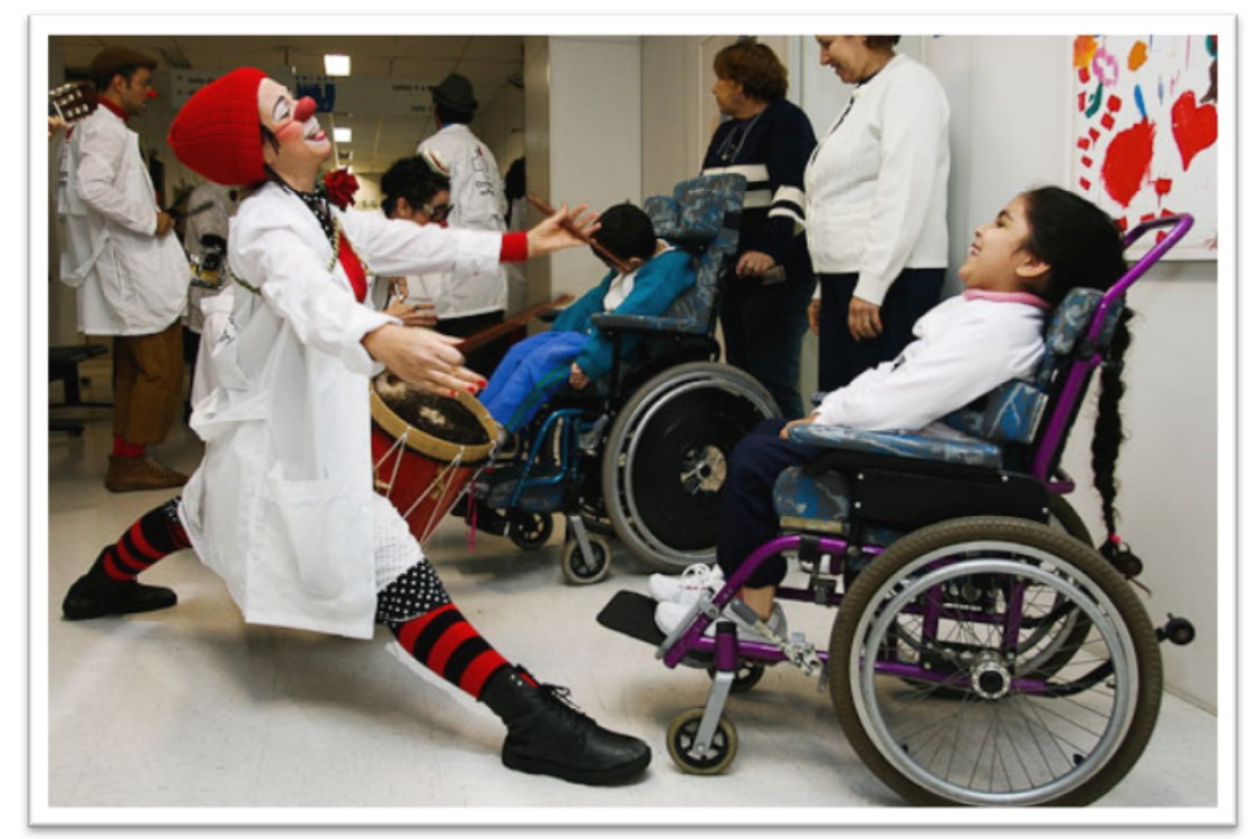

Figura 1. Doutora Lola Brígida (Luciana Viacava) atuando no hospital. São Paulo, 2014. Foto do acervo digital Doutores da Alegria. Fonte: <doutoresdaalegria.com.br $>$ Acesso em 09/04/2019 
Quais são os desafios desta contemporânea e crescente manifestação cênica? Quais são as diferenças e semelhanças entre a atuação das palhaças e dos palhaços no contexto hospitalar e em outros espaços da sociedade? Essas e outras questões são abordadas por Luciana Viacava, que ao tecer estas palavras, teve como pano de fundo as suas experiências pessoais enquanto palhaça e artista da comicidade.

\section{Entrevista}

\section{Luciana, você poderia informar desde que ano você atua como palhaça na} ONG Doutores da Alegria?

Entrei no ano de 2006. Havia feito duas vezes o teste para entrar na ONG, em anos diferentes, e não passei. Na terceira vez em que fiz o teste também não passei, então a Thaís (Thaís Ferrara - atual Diretora de Formação dos Doutores da Alegria) me chamou para conversar e perguntou: "O que acontece?" Eu falei: "Não sei... eu não gosto de testes... acho que fico nervosa..." Ela resolveu arriscar e apostou em mim. Estou aí até hoje!

\section{Antes de atuar nos Doutores da Alegria você teve experiências como artista no contexto hospitalar?}

Tive pouca experiência. Eu tinha muita vontade de trabalhar nos Doutores da Alegria. Depois da primeira vez em que fiz o teste e não passei, fui trabalhar com o grupo Risomundi, onde trabalhavam, na época, três amigos palhaços; o Dênis Goyos, o Alan Benatti e a Gabriela Argento. Fiquei pouco tempo no grupo. Fazíamos visitas a laboratórios, aos sábados. Além disso, fui uma vez com a Daniela Biancardi fazer uma visita como palhaça em um hospital em Jundiaí. E em outra ocasião, com o grupo As Meninas do Conto, contar histórias em um hospital em SP.

\section{Você poderia falar sobre sua trajetória artística e experiências que te levaram a atuar como palhaça no contexto hospitalar?}

Curiosamente, o que me levou a essa trajetória artística foi um contexto hospitalar. Eu tinha 22 anos, tinha feito faculdade de Rádio e TV e trabalhava no SBT. Eu era Coordenadora de Elenco do Núcleo de Novelas, ou seja, selecionava os atores para variadas participações nas novelas. Mas daquele lugar eu pensava: "Eu devia estar do outro lado", pois sempre adorei fazer teatro, desde criança, mas não pensava nisso como profissão. Naquela época, eu trabalhava demais e um dia, voltando para casa, sofri um acidente. Dormi na direção, fui levada para o hospital e quando acordei, havia perdido uma vista. Foi bastante traumatizante, fiquei muito abalada, demorei para me recuperar, sobretudo, emocionalmente. Resolvi fazer algo que me desse prazer e entrei num curso de teatro, no Teatro Escola Célia Helena.

No Célia Helena, ouvi falar dos Doutores da Alegria e aquilo me chamou a atenção, principalmente por acontecer em contexto hospitalar. Sobre o palhaço eu não sabia nada até então, mas tinha uma grande empatia com essa figura. Quando eu estava 
quase no fim do curso, fiz uma oficina de clown com o Fernando Vieira no Galpão dos Acrobáticos Fratelli. Aí a coisa bateu forte. Falei para mim mesma: "É isso o que eu quero fazer da vida!" A palhaça foi uma grande liberdade para mim, logo de cara me dei bem, as pessoas riam e eu me sentia feliz. No fim dessa oficina, o Fernando Vieira nos deu uma lista de referências, filmes e escolas pelo Brasil e o mundo onde se poderia estudar essa linguagem. Terminei o curso no Célia Helena e resolvi ir para a École Internationale de Théâtre Jacques Lecoq em Paris. Eu já falava francês, tinha ganhado um bom dinheiro na televisão e resolvi me lançar nesta aventura. Aí fui conhecer um mundo totalmente novo para mim e me apaixonei. Apaixonei-me pelo estudo do movimento, pelas máscaras e pelo teatro gestual.

Fiz o primeiro ano da escola em Paris e depois fui para a Itália, em Pádua, e fiz o equivalente ao segundo ano da escola com Giovanni Fusetti na Kiklos Scuola. Lá entrei em contato com a figura do bufão, com as máscaras da Commedia dell'Arte e com o palhaço. Logo que voltei fiz o teste nos Doutores da Alegria, mas não passei. Então fui cuidar da vida. Trabalhei com vários grupos de teatro, fiz contação de histórias, dei aulas de francês, aulas de teatro, trabalhei como palhaça em eventos, estudei com outros mestres, como Cristiane Paoli Quito, Bete Dorgan, Phillipe Gaulier, entre tantos outros, até que em 2006 entrei nos Doutores da Alegria, algo muito importante para mim até hoje. O palhaço é uma eterna pesquisa. Estou sempre estudando e procurando me aprimorar. Até hoje faço oficinas de palhaço, estudo música e instrumentos musicais e procuro manter o corpo disponível para o trabalho.

\section{No seu trabalho como palhaça, você emprega técnicas específicas? Quais?}

O trabalho varia um pouco conforme o contexto, pois trabalho em hospital, em circo, no teatro e na rua e cada espaço demanda uma forma de trabalhar. Mas as técnicas que uso são as que aprendi ao longo do caminho: a primeira coisa é criar conexão com o público, empatia, saber ler e ouvir seu público e estabelecer relação. Depois vem as técnicas do jogo da máscara como a limpeza dos gestos e ações, a economia de movimentos, os níveis de energia, a comicidade física, a improvisação, além de habilidades musicais como o canto e a percussão. Mas acredito que depois de tanto tempo trabalhando como palhaça dentro e fora do hospital, a técnica acaba ficando impregnada, deixa de ser técnica e passa a ser jogo.

\section{Considerando sua experiência, você identifica semelhanças e diferenças quan- to à atuação no espaço do hospital e em outros lugares da sociedade? Quais?}

Para mim o palhaço é palhaço onde quer que esteja. Não importa se está em um hospital, num circo ou em uma praça. Não existe palhaço de hospital, palhaço de circo, etc. Existe palhaço em hospital, em circo ou na rua. Ou seja, a essência é a mesma em todos os lugares. O que muda no contexto é o tamanho do gesto, o volume da voz, a relação com o espectador. Muitas vezes no hospital você atua para uma pessoa, enquanto que no circo você está para várias pessoas ao mesmo tempo. Ou seja, a percepção do espaço, a escuta, o olhar, o jogo, o corpo, a voz, o raciocínio palhacesco, a relação com os parceiros de cena e com o público tem que estar presentes em todos os contextos. 


\section{Quais são seus objetivos e desafios enquanto palhaça que atua no contexto hospitalar?}

Basicamente o objetivo é conseguir estabelecer relações de jogo com todas as pessoas com quem encontro: meu parceiro, as crianças, seus acompanhantes, os funcionários, médicos e enfermeiros, levando ao cotidiano desse contexto, um olhar diferente sobre a realidade, através da arte do palhaço. $E$ também aprimorar-me enquanto artista, enquanto palhaça e ser humano.

Um grande desafio enquanto artista/palhaça é saber lidar com as diferentes formas de jogo dos parceiros com quem vou trabalhar. Cada palhaço tem um jeito, vem de uma escola diferente; e encontrar uma boa escuta, um bom jogo que traga encontros potentes no dia a dia, não é tão evidente, leva tempo e é uma conquista.

Outro desafio é treinar o olhar para buscar na criança o lado saudável dentro da doença e fazer com que isso se manifeste de alguma forma. $E$ também buscar um modo de não se deixar levar pela tristeza. Como manter o estado do palhaço em situações difíceis e limites? Como sair do hospital e não carregar todo o peso do ambiente? Como não cair no cotidiano? Como manter o estado de jogo durante horas seguidas? No dia a dia do trabalho vamos lidando com essas questões.

\section{Considerando sua experiência, que elementos você identifica como compo- nentes da comicidade na atuação hospitalar?}

O hospital é um ambiente extremamente delicado, por isso o artista/palhaço tem que ter em mente que mais importante é saber ouvir o outro e não querer impor sua presença a qualquer custo. Muitas vezes você tem que abrir mão de uma bela gague, de uma habilidade ou de uma piada incrível, pois a situação pede outra coisa. Às vezes uma música bonita e bem executada comunica muito mais do que um riso arrancado a qualquer custo. É claro que enquanto palhaços buscamos a graça, mas às vezes um olhar que se modifica já é para nós um ganho. A comicidade pode aparecer de diversas formas, como em um figurino estranho, o clássico sapato grande, as roupas muito largas ou muito justas, os movimentos corporais não cotidianos, um discurso absurdo com a lógica de cada palhaço, a ressignificação de objetos, situações, pequenas cenas, habilidades musicais, mágica, claques, cascatas e tudo o que compõe o repertório do palhaço.

\section{Você gostaria de relatar experiências significativas ao longo de seu processo enquanto palhaça no contexto hospitalar?}

A gente passa por muitas experiências fortes e significativas, mas acredito que as que ficam mais marcadas na memória sejam aquelas que acontecem quando temos uma relação mais aprofundada com a criança e seus familiares. Em um hospital como o Itaci (Instituto de Tratamento do Câncer Infantil), onde as crianças ficam internadas por muito tempo, temos a oportunidade de construir uma relação de amizade e confiança com eles, e esse é um ponto muito importante no trabalho dos Doutores da Alegria: a regularidade das visitas. Fazemos visitas duas vezes por semana, no mesmo hospital, com a mesma dupla, durante um ano, o que nos possibilita criar 
vínculos com nosso público.

Uma boa história aconteceu no Itaci, onde eu trabalhava com a Juliana Gontijo, a Dra. Dona Juca Pinduca. Um dia, cada uma de nós ganhou um presente de uma menina: uma caixinha de origami com um colar e uma pulseira, tudo feito por ela. Para a Juca um conjunto amarelo, para mim, um conjunto verde. Vestimos os colares e pulseiras e saímos todas pomposas pelo corredor. $\mathrm{O}$ quarto seguinte era o quarto de uma menina que já conhecíamos e que era nossa amiga. Entramos e percebemos que ela estava com a cara fechada. Olhamos para o pai, buscando querer entender o que estava acontecendo. Ele falou:

-Ela está com medo.

-Medo de que?

-Medo da quimioterapia.

Fiquei sem saber como lidar com aquilo, pois era um elemento muito concreto, que fazia parte da dura realidade da menina. Como levar isso para a palhaça? A Ju, mais experiente, lembrou de uma história de medo de sua infância. Como ela estava com colar e pulseira amarelos, começou: "Era uma vez uma princesa amarela (com voz de terror), que morava num castelo amarelo, usava um vestido amarelo. Um dia a princesa amarela encontrou um fantasma azul - depois, com a voz fininha, falou: aí juntou com o amarelo e ficou tudo verde." Quando ela falou verde eu peguei a bola pra mim e disse: "Era uma vez uma princesa verde, que morava em um castelo verde..." e comecei a repetir toda a história da Juca, até que falei: "Um dia ela encontrou um dragão verde..." A Juca me interrompeu:

- Lola, dragão não existe.

E a menina, que estava quieta até então, retrucou, apontando pra Juca.

- Existe, sim! Tem um bem aqui na minha frente! (e caímos todos na risada). Esta história ficou marcada porque me ensinou muito sobre esse ofício e sobre a vida. Nós não fugimos do assunto, não fingimos que o medo não existia, pegamos o que tínhamos ali de material para trabalhar: o tema proposto pelo pai, os adereços que tínhamos acabado de ganhar, alguma imaginação e conseguimos reverter a situação. A menina de cara fechada já não estava com medo, entrou no nosso jogo e se deixou levar por seu lado saudável. É impressionante a capacidade que as crianças têm de jogar.

Outra história aconteceu no mesmo hospital também com a Doutora Juca. Conhecemos um menino de 12 anos, aproximadamente, muito divertido, animado, uma graça. A mãe também era muito alegre e divertida. Criamos uma bela relação de confiança através do jogo das palhaças. Eu dizia que ele era meu noivo, ele só ria e a mãe brincava:

- Ai, eu não quero esta nora pra mim!

Vivíamos brincando com esse tema. Um dia eu ia vestida de noiva para casar, outro dia falava dos planos de ter filhos, assim por diante. E eles sempre acabavam comigo. Só que ele foi piorando, ficando muito fraquinho. A mãe, transtornada pela situação do filho, ainda passava por grandes problemas em casa com o marido. Um dia nos encontramos no corredor do hospital e ela me chamou: "Lola, vem cá!" Eu e a Juca nos aproximamos e ela foi me puxando pela saia que começou a rasgar, pois já estava meio velhinha. Então ela gostou de rasgar minha saia, foi se animando e começou a rasgar cada vez mais. Eu tirei a saia e deixei que ela rasgasse tudo. Ela 
descontou toda a sua frustração na saia da nora que não queria ter. Foi um misto de raiva e alívio. Eu e a Juca ficamos muito impressionadas e nos questionamos sobre a função do palhaço numa situação como essa. Nesse caso acho que fomos uma espécie de para-raios. Graças à confiança mútua que já tínhamos conquistado, eu sabia que ela não iria me machucar e ela sabia que eu não iria julgá-la por sua atitude. Pouco depois disso, o menino morreu e nós não nos vimos.

\section{Você acredita que seu trabalho como palhaça gera experiências que modificam sua maneira de viver no mundo? Se sim, de que forma?}

Meu trabalho como palhaça me realiza enquanto ser humano e creio que isso já seja uma boa maneira de viver no mundo. Essa realização não é eternamente plena, ou seja, não é estática, está sempre oscilando e isso me leva ao movimento, me leva a buscar um aprimoramento no trabalho e na vida, um refinamento maior. Sou muito rígida comigo e o palhaço me ajuda a transformar a rigidez em rigor, que me parecem duas faces da mesma moeda. O palhaço está sempre jogando, se divertindo, ele traz à tona muitas vezes o que ninguém quer ver, mas que precisa ser visto, falado, mexido. E faz isso sem ofender, sem apontar o dedo, sem ser agressivo. Faz por pura ingenuidade, sem se dar conta, como uma criança. Isso é um grande aprendizado para a vida. O palhaço é um provocador. $E$ para isso, o artista tem que estar conectado ao seu tempo sem perder de vista as referências antigas, os ensinamentos de grandes palhaços e mestres que já trilharam esse caminho.

\section{Considerações finais}

Gerar rupturas no cotidiano de maneira cuidadosa e respeitosa em relação ao público a que as figuras palhacescas vão de encontro no contexto hospitalar, como vimos a partir do depoimento de Luciana Viacava, pode tratar-se da mescla entre o desenvolvimento de uma gama de técnicas e práticas específicas com as sensibilidades de cada artista, gerando momentos de encontro entre as Artes Cênicas e a vida cotidiana.

$\mathrm{Na}$ fala de Luciana Viacava percebe-se um constante investimento em preparo técnico, vivências investigativas, estudos e práticas que a instrumentalizam enquanto palhaça e formadora. Observa-se, ainda, a preocupação da artista em não sobrepor essas técnicas cênicas à escuta das proposições de cada encontro hospitalar, tendo por objetivo central a realização de comunicações positivamente efetivadas.

Trata-se de investigar uma atuação cênica deslocada da espetacularidade e fundada no jogo com os momentos de encontro e com cada relação possível no dia-adia. Os repertórios tradicionais do circo, elementos pré-expressivos do teatro, habilidades musicais, e outras ferramentas, como vimos, muitas vezes são a porta de entrada para uma comunicação positivamente efetivada, material para o aprofundamento de uma relação delineada pela comicidade e que se prolonga ao longo das semanas, meses e anos.

Como foi evidenciado nesse material de registro, os Doutores da Alegria desenvolvem e fomentam a pesquisa profissional sobre a atuação palhacesca hospitalar, assim como as palhaças e palhaços que atuam nessa instituição. Ao longo de quase 
três décadas a ONG vem trazendo novos olhares e ampliando as possibilidades de inserção das figuras palhacescas na sociedade, incentivando e promovendo ações de formação voltadas para grupos e indivíduos, promovendo a profissionalização de jovens e de adultos, produzindo materiais bibliográficos sobre a atuação palhacesca hospitalar, entre outras atividades.

Elaborado a partir do generoso compartilhamento de algumas experiências e percepções de Luciana Viacava, as quais foram delineadas desde uma sólida trajetória na palhaçaria e na palhaçaria hospitalar, esse registro intenta contribuir com a investigação da palhaçaria hospitalar como tempo e espaço de conjunção entre técnicas e sensibilidades.

\section{REFERÊNCIAS}

BRUM, Daiani Cezimbra Severo Rossini. A atuação de palhaças e de palhaços: o hospital como palco de encontros. 2017. 138f. Dissertação (Mestrado) - Curso de Artes Cênicas, Departamento de Artes. Universidade Federal do Rio Grande do Norte, 2017.

DOUTORES DA ALEGRIA (São Paulo). Site dos Doutores. 2015. Disponível em: <www.doutoresdaalegria.org.br>. Acesso em: 07 mai. 2016.

MASETTI, Morgana. Soluções de palhaços: transformações na realidade hospitalar. São Paulo: Palas Athena, 1998.

SENA, Antônio Geraldo Gonçalves. Doutores da Alegria e profissionais de saúde: o palhaço de hospital na percepção de quem cuida. 2011. 95 f. Dissertação (Mestrado) - Curso de Enfermagem, Escola de Enfermagem. Universidade Federal de Minas Gerais, 2011. Disponível em:

<http://www.bibliotecadigital.ufmg.br/dspace/bitstream/handle/1843/GCPA-8KUHE9/antonio_geraldo_gon_alves_sena.pdf?sequence=1>.

Recebido em 16/10/2018 - Aprovado em 09/04/2019

Como citar:

Brum, D. (2019) A palhaçaria hospitalar como conjunto de técnicas e sensibilidades: entrevista com Luciana Viacava. OuvirOUver, 15(2), 220-230. https://doi.org/10.14393/OUV24v15n1a2019-15 